differences in the art and languages of the two cultural centres. On present evidence, any other assumption would leave far too much to coincidence $^{9}$. In the final analysis it is not so much a question of the mere use of script as of the conditions responsible for the original emergence of writing.

At all events, Egyptian writing, regardless of its origin, inevitably played its part in the notable progress of Egyptian science. What we miss here, however, is the seope and inner unity of scientific advance which are found to be so characteristic of Mesopotamia. That unity was the product of a tradition which is traceable ultimately to a particular concept of life. In totalitarian Egypt a different set of values attached to life and government and tradition. Is this the reason for an effort that seems more sporadic, greater perhaps in its power of concentration on specific objectives, but also more conspicuous for its omissions? Over a period of millennia this appears to be a justifiable comparative appraisal of the results achieved in the field of science by the two oldest historic civilizations.

\footnotetext{
1 These facts are brought out clearly by A. Falkenstein, whose "Archaische T'exte aus Uruk" (Berlin, 1936) is the basic work on the earliest documents from Mesopotamia ; cf. especially pp. $43 \mathrm{ff}$.

${ }^{2}$ Careful observation is evidenced also by the accurate drawings of the early pictographs, particularly where exotic animals and specific plants were concerned.

${ }^{3}$ See Benno Landsberger (in co-operation with I. Krumbiegel), "Die Fauna des alten Mesopotamien" (Leipzig, 1934).

" On this subject see R. Campbell Thompson, "A Dictionary of Assyrian Chemistry and Geology" (Oxford, 1936).

${ }^{5}$ R. Campbell Thompson and C. J. Gadd, in Iraq, 3, $87 \mathrm{ff}$. (1936).

"Cf. E. A. Speiser, "The Beginnings of Civilization in Mesopotamia," $J$. Amer. Oriental Soc., Supp. 4, 59, 17 ff., esp. 25-28 (1939).

"See H. Frankford, "Cylinder Seals" (London, 1939), p. 2.

8 Note the article by V. Gordon Childe, on "The Oriental Background of European Science", Mod. Quarterly, 1, No. 2, 105 ff. (1938).

- Cf. Speiser, op. cit., 22, note 12, and Siegfried Schott, in Kurt Sethe's "Vom Bilde zum Buchstaben" (1939), pp. 81 ff.
}

\title{
BROADCASTING IN INDIA
}

$\mathrm{T}$ HE task of providing an efficient radio broadcasting service in the Indian Empire is beset with many problems which are peculiar to that country and which other broadcasting organizations in Europe and America have not encountered. India is a country of relatively great distances and a vast population, most of whom have a rather low standard of living. Nearly thirty times the area of England, the population numbers more than 300 millions, speaking some 200 different languages, of which about 16 are in common use. From a technical point of view India is subject to a frequent and very high atmospheric disturbance level, and this calls for special consideration in the choice of wave-length and power of the transmitting stations, if a satisfactory programme service free from interference is to be obtained. Furthermore, it was clear many years ago that a broadcasting service could not be built up out of licence revenue as was done in Great Britain. These and other problems have occupied the attention of the Government of India over the past thirteen years, since the first broadcasting station was opened at Bombay by Lord Irwin in July 1927. In his speech on this occasion the Viceroy indicated that India offered special opportunities for the development of broadcasting, and that although it was then in its infancy, he had little doubt that, before many years had passed, the numbers of its audience would have increased very considerably and that this new application of science would have its devotees in every part of India.

The long and varied struggle which the Indian State Broadcasting Service has had since the date mentioned above is recounted in a recent publication from Delhi entitled "Report on the Progress of Broadcasting in India, up to the 31st March $19399^{\prime *}$. A second broadcasting station was opened at Calcutta in 1927, by the end of which year the number of licensed listeners was less than 3,600 . Although this number was soon doubled, the rate of increase remained sensibly unaltered from 1929 until 1932, when the inauguration of the Empire Service of the British Broadcasting Corporation led to a sharp rise in the rate of increase to more than 16,000 listeners by the end of 1934, although there were still in operation at this time only the two broadcasting stations already mentioned. Soon after this time, the first Controller of Broadcasting of the Government of India assumed charge of the organization known as All India Radio, and set to work to develop broadcasting into a service appropriate to the needs of the country. In view of the lack of technical experts in India with any long experience in broadcast engineering, considerable assistance was obtained in this connexion from the B.B.C. in Great Britain.

The development policy, upon which work has been actively progressing during the last two or three years covered by the report, envisaged the establishment of nine medium-wave stations and five short-wave stations, one of which, situated at Delhi, was specially assigned for the transmission of news from a central point. The basis of the scheme of using medium-wave stations operating on wave-lengths between 200 and 400 metres followed the experience gained in Europe and

* Report on the Progress of Broadcasting in India up to the 31st March 1939. Pp. xiv $+230+21$ plates. (Delhi: Manager of Publications, 1940.) 3 rupees; 58 . 
America, and it was considered that the nine stations projected would provide a first-grade medium-wave service at important centres of population. In order to reach the rural population, however, it is necessary to spread the service over relatively great distances and this factor, together with the prevalence of some atmospheric disturbances, led to the supplementary scheme of the provision of short-wave transmitting stations. The application of short wave-lengths to Indian broadcasting differs in one very important aspect from the application made by European countries, in so far as in India the short-waves were required for an internal broadcasting service, whereas in European countries the short-wave service is primarily intended for overseas listeners. This difference in requirements leads to the use of different wave-length bands in the two cases, and therefore fortunately to an absence of interference. The Indian short-wave stations normally operate in the day-time in the wave-length bands of 30 and 49 metres, which are used by the European international stations only at night; while in India at night, the wave-length bands of 60 and 90 metres are utilized, and these are not used by broadcasting stations operating an international service.

At the inauguration of the above scheme, it was estimated that if the short-wave transmitters were of a power rating of 10 kilowatts they would have an intelligible, if not satisfactory, service range of about 500 miles. The four stations projected for general use could therefore be regarded as covering the whole of India, and providing a service which, if not entirely free from fading, would be not unsatisfactory to the average listener. The installation of four such stations instead of one high-power medium-wave station possessed a marked advantage in providing the possibility of alternative programmes which, owing to diffculties arising from timings, languages, Indian and European music and so forth, would clearly be very desirable. During the years 1937 and 1938 the four short-wave stations came into operation, and these, together with the new and already established medium-wave stations, resulted in twelve of the fourteen projected stations being in service use at the date of presentation of the report referred to above. The whole scheme was financed by a capital grant from the Government of some $£ 300,000$, from which a balance of about $£ 120,000$ remained on April 1, 1939. The overall annual expenditure of the All India Radio organization has risen steadily to nearly $£ 190,000$ for the year 1938-39.

In the early days, the engineering and technical control of broadcasting in India was conducted by the Posts and Telegraphs Department. Afterwards these activities were transferred to All India Radio under the Controller of Broadcasting, in order to avoid the admitted difficulties of divided control between administration and programmes and engineering. Considerable space is given in the Controller's report to the activities of the Engineering Department, which is concerned mainly with the maintenance and operation of existing broadcasting stations; the planning and installation of new broadcasting centres; and with development and research work of a technical nature.

Any broadcasting system must make extensive use of direct connexions between the various stations so that programmes originating at one station may be radiated from others. These connexions are usually effected by telephone lines suitably designed and installed for the purpose; but in India they present a special problem owing to the immense distances separating the broadcasting stations and the general unsuitability of the telephone lines and associated apparatus. All India Radio has consequently developed a system of wireless links whereby each broadcasting station is provided with a receiving centre equipped with special directional aerials for accepting programmes from the desired stations. These receiving centres are used principally for picking up the short-wave transmissions of All India Radio and of the B.B.C., and relaying these from the local transmitter. In the same way the news bulletins of the Central News Organization at Delhi will, as receiving centres are established, be received and relayed by all stations in the system. The main receiving centre on the outskirts of New Delhi was installed and working on a temporary basis just in time to relay the Coronation ceremony broadcast by the B.B.C. in May 1937. The installation utilizes a combination of three directional aerials for diversity reception to minimize the fading commonly experienced in short-wave broadcasting. The New Delhi receiving station also acts as a main control centre where a watch is kept on the wave-length, field strength and quality of the transmissions from stations of the All India Radio.

Among the more important activities of the research department of the organization is a study of the field strength of the transmissions from the various stations and of the service area of each station as determined by the ratio of the field strength of the signal to the strength of the disturbing noise. Much useful material on these subjects is given in the report under discussion, but only one or two outstanding points can be referred to here. One interesting fact emerging from the measurement of the field strength of the radiation from the various medium-wave stations is that the decrease in intensity of the ground wave with increasing distance from the 
transmitter shows that the conductivity of the soil in India is of the same order as that obtained under average conditions in England (that is, between 1 and $2 \times 10^{8}$ x.s.U. or $4,500-9,000$ ohm-cm.). In addition to a study of ground wave conditions, measurements have also been carried out at night time on the indirect ray field strengths of the medium-wave stations. The results show that, with one or two exceptions that remain for further investigation, the relation between distance and field strength of these stations approaches the curve published by the C.C.I.R. (International Committee on Radio Communication), which is based upon a very large number of measurements made by broadcasting organizations in various parts of the world. This fact indicates that the conditions of medium-wave propagation through the ionosphere in India are not appreciably different from those in other parts of the world.

As already mentioned, the effective service area of a broadcasting station is determined by the ratio of the strength of the wanted signal to that of the unwanted noise. During the summer months of May-October, atmospheric disturbances represent the greatest single technical difficulty to be met with in India in providing a satisfactory broadcasting service, especially on the medium wave-length band. It is natural, therefore, to find that a considerable study is being made into the nature and origin of atmospheric disturbances. It is interesting to observe, however, that on the short wave-length bands, the service area of the Indian broadcasting stations is at present limited by the noise from electrical machinery and not by atmospherics. By far the most serious limitations on short-wave reception in India is the noise resulting from the operation of ceiling fans from a direct-current supply. In practically every city in India a D.c. supply only is available, and only in the large cities is a gradual change-over to alternating current supply being made. During the summer months, for a greater part of the twenty-four hours, there is a number of D.C. motor-driven fans in operation, and in many of these the commutator is in an unsatisfactory condition and hence causes serious disturbance.

As a conclusion to this review of the present state of broadcasting in India, reference will be made to a somewhat unusual activity of a broadcasting organization, namely, the design, supply and maintenance of a communal receiver for use by a considerable proportion of the rural population. From what has been stated earlier in this article it will have been appreciated that, apart from a few towns and suburbs, the broadcasting service in India is maintained by means of indirect rays propagated through the ionosphere, and if all-the-year-round reception is desired, the receiver must be one of the short-wave type, which is by no means cheap. The bulk of India's population live in villages, and it is considered that nearly 99 per cent of them cannot afford to buy any radio receiver, however reasonable its cost may be. The only solution to this economic difficulty appeared to be the installation of community receivers and the provision of special programmes for the villages. A number of such receivers has been installed by, and maintained at the expense of, the Governments of the individual provinces and are very successful.

As a number of difficulties were met with in the earlier stages of the inauguration of the village receiver scheme, a study of the technical points involved was made by the Research Department of All India Radio. After adequate investigation of the requirements, a specially designed receiver was evolved which, while following the general trend of commercial practice, incorporated certain additions and modifications. The receiver is of a straightforward superheterodyne type suitable for operation from a 6-volt car accumulator. In the comparatively few cases where an alternating current electric main supply is available a suitable alternative type can be provided. The two main requirements involved in the design of these receivers are reliability of operation and economy, since it is desired that they shall work automatically with only occasional attention by skilled technical personnel.

The receivers themselves are mounted in padlocked metal boxes, designed to keep out dust and insects. No controls appear on the outside of the box, and the receiver is left tuned to the local station. A clockwork-driven time-switch, incorporated in the set, switches the receiver on and off at the correct time for the "Village Hour" of broadcasting. Special attention has been given to the loud-speaker, which has been designed to have a high electrical acoustical conversion efficiency, to be free from the ravages of dust and moisture, and to give an adequate output of reasonable quality suitable for an audience of some two hundred listeners. The present type of receiver can be run from a medium-size car battery for a month on the basis of one hour's listening per day. Every three or four weeks the battery is charged and the clock re-wound. Installations of this type varying from fifteen to a hundred and twenty receivers in various provinces are in process of completion. In this manner, the full possibilities of community listening in numerous villages are being explored in an attempt to make broadcasting available to as great a proportion of the population of India as possible. 